\title{
Associations between attitudes towards scientific misconduct and self-reported behavior
}

Søren Holm ${ }^{1,2}$ and Bjørn Hofmann ${ }^{2,3}$

\footnotetext{
${ }^{1}$ Centre for Social Ethics and Policy, School of Law, University of Manchester, Manchester, UK;

${ }^{2}$ Centre of Medical Ethics, University of Oslo, Oslo, Norway;

${ }^{3}$ Institute for the Health Sciences, Norwegian University of Science and Technology, Gjøvik, Norway
}

\section{Corresponding Author: Søren Holm}

Key words: dishonesty, doctoral students, fabrication, falsification, plagiarism, misconduct, misbehavior, integrity, science ethics 


\begin{abstract}
We investigate the relationship between doctoral students' attitudes towards scientific misconduct and their self-reported behavior. 203 questionnaires were distributed to doctoral candidates at the Faculty of Medicine, University of Oslo 2016/2017. The response rate was $74 \%$. The results show a correlation between attitudes towards misconduct and self-reported problematic behaviors among doctoral students in biomedicine. The four most common reported misbehaviors are adding author(s) who did not qualify for authorship (17.9\%), collecting more data after seeing that the results were almost statistically significant (11.8\%), turning a blind eye to colleagues' use of flawed data or questionable interpretation of data (11.2\%), and reporting an unexpected finding as having been hypothesized from the start (10.5\%). We find correlations between scientific misbehavior and the location of undergraduate studies and whether the respondents have had science ethics lectures previously. The study provides evidence for the concurrent validity of the two instruments used to measure attitudes and behavior, i.e. the Kalichman scale and the Research Misbehavior Severity Score (RMSS). Although the direction of causality between attitudes and misbehavior cannot be determined in this study the correlation between the two indicates that it can be important to engender the right attitudes in early career researchers.
\end{abstract}




\section{Background}

Our knowledge about scientific misconduct is increasing. We know that there are non-negligible rates of serious misconduct, e.g. fabrication, falsification and plagiarism in many areas of academic research; and that other types of misconduct, e.g. authorship misconduct and problematic data manipulation are even more prevalent ((de Vries, Anderson, and Martinson 2006, Martinson et al. 2006, Anderson, Martinson, and De Vries 2007, Redman, Yarandi, and Merz 2008, Marusic, Bosnjak, and Jeroncic 2011, Hofmann et al. 2015a, Bozeman and Youtie 2016, Saurin 2016, Fanelli 2009, John, Loewenstein, and Prelec 2012, Pupovac and Fanelli 2015, Pryor, Habermann, and Broome 2007, George 2016, Bakker and Wicherts 2011, Tijdink, Verbeke, and Smulders 2014, Tijdink et al. 2016, Ana et al. 2013, Ranstam et al. 2000, Davis, Riske-Morris, and Diaz 2007, Lafollette 2000, Sarwar and Nicolaou 2012, Fang, Bennett, and Casadevall 2013, Stern et al. 2014, Okonta and Rossouw 2014, Komic, Marusic, and Marusic 2015). We also have some knowledge about the factors that are correlated with or causally linked to scientific misconduct, such as publication or funding pressures, general scientific culture and personality types (Tijdink et al. 2016, Martinson et al. 2009, DuBois et al. 2013, Fanelli 2010). In this study our aim to add to this growing literature by exploring two issues. First we investigate the relationship between doctoral students' attitudes towards scientific misconduct and their self-reported problematic behavior. Our hypothesis is that the more their attitudes are in accordance with generally accepted norms in research integrity, the fewer instances of misbehavior or misconduct will they report.

Then we address the issue of which background factors that are important for the severity of reported research misbehavior. We hypothesise that none of the following factors are associated with increased reporting of misconduct: gender, type of research, where the candidate did his undergraduate studies, or whether the candidate previously had attended lectures or courses in science ethics.

In addition to providing new knowledge on the link between attitudes and misconduct, this study offers input as to where to direct our attention and resources in order to improve research integrity. Progress and success in science depends on trust. To maintain and increase this trust is of the utmost importance for researchers, the scientific community, and for society in large.

\section{Materials and methods}

A two-page questionnaire with questions on knowledge of, attitudes to, and behavior with respect to various forms of scientific misconduct was used. The questions on knowledge and actions stem from a survey developed at the Department of Medical Ethics in Lund, Sweden (Nilstun, Lofmark, and Lundqvist 2010), while the questions on attitudes stem from a recently validated survey originally developed by Kalichman (Kalichman and Friedman 1992, Holm and Hofmann 2017). A questionnaire with these elements has been used previously in studies in Norway, Sweden and Denmark (Hofmann, Myhr, and Holm 2013, Hofmann and Holm 2016, Hofmann et al. 2015b, Jensen et al. 2018). The Research Misbehavior Severity Score (RMSS) from a Dutch study (Tijdink et al. 2016) was added to 1) enable a comparison between two different methods for quantifying self-reported problematic behaviours, and 2) to derive data for a possible concurrent validation of the Kalichman and RMSS scales. 
The Kalichman questionnaire contains 14 statements concerning attitudes towards misconduct, such as "It is never appropriate to report experimental data that have been created without actually having conducted the experiment" (S1 contains all the statements). The statements are scored on a 5 point Likert scale from "completely disagree" to "completely agree". We have previously shown the psychometric validity of a 13 question scale, and 4 sub-scales derived from this questionnaire (Holm and Hofmann 2017). Scores for the total scale and sub-scales are formed by simple addition, with two items being reverse scored.

The RMSS contains 22 questions concerning self-reported scientific misbehaviour, such as "Fabricated data?". The questions are scored on a 5 point scale from "0 times" to "Always" (S2 contains all the statements). The RMSS score is constructed by translating the scores of the items dichotomously (behavior yes/no) and assigning the items different weights according to the severity of the behavior, as described in (Tijdink et al. 2016):

"The most severe type of misbehavior (based on the definition of fraud, i.e. fabrication, falsification and plagiarism) was 3 points. The other item scores were based on consensus in the research group and were assigned 1 (for moderate) and 2 (for severe) misbehavior. Positive answers (committing the behavior at least 'once' in the past 3 years) to the most severe misbehavior questions (items $1,2,8,9,12,15$ and 19) were assigned three points, positive answers of the severe research misbehavior questions were assigned two points (items $4,7,10,14,16,18$ and 20) and positive answers to the moderate research misbehavior questions were assigned one point (items 3, 5, 6, 11, 13, 17, 21 and 22). Scores were added up to calculate the composite research misbehavior severity score (RMSS) (maximum range: 0-43)." (Tijdink et al. 2016)

Terms such as 'scientific dishonesty', 'plagiarism', 'fabrication of data', and 'falsification' were given standard definitions at the beginning of the questionnaire.

The participants in the study were post-graduate students enrolled in the PhD program at the Faculty of Medicine, University of Oslo in Norway. The questionnaire was printed on yellow paper and distributed to doctoral students attending basic, compulsory courses in research methodology, philosophy of science, and research ethics in the academic year 2016/2017. The questionnaires were anonymous and participation was voluntary, which was emphasised both in the introduction letter and when handing out the questionnaires. Students could complete the questionnaire at a time and place of their own choosing and return was in an unmonitored box thereby ensuring complete anonymity.

The data was analysed using standard statistics functions in SPSS 24. Because both the Kalichman scale and the RMSS data is non-normally distributed the analyses used non-parametric methods.

No personal data traceable to individual participants was registered, and the study was thus not subject to REC/IRB approval, in accordance with Norwegian law. Participants consented to participating in the study by filling in and handing in the form.

\section{Results}


203 questionnaires were distributed, of which 166 were returned and 150 were valid. The overall response rate was $73.89 \%$ (81.77\%). Table 1 gives an overview of the demographical data for the respondents.

Table 1 Demographical data for the respondents of the survey

\begin{tabular}{|l|l|c|}
\hline N = 150 & Category & No. \\
\hline Gender & Male & 51 \\
& Female & 79 \\
\hline Kind of research & Clinical Research & 76 \\
& Basic Research & 35 \\
& Other Research & 16 \\
\hline Duration of doctoral & Less than or equal to 1 year & 98 \\
study & 1-2 years & 27 \\
& More than 2 years & 4 \\
\hline Lectures or courses in & Yes & 89 \\
science ethics as an & No & 16 \\
undergraduate & Can't remember & 24 \\
\hline Location of & Norway & 91 \\
undergraduate studies & Sweden & 34 \\
& Other & 6 \\
\hline
\end{tabular}

We analysed the relation between demography and RMSS scores using Kruskal-Wallis and MannWhitney tests. The analyses show that persons who had their undergraduate studies in Sweden had a higher RMSS score than those who had studied in Norway or elsewhere. See table 2. We further found that those not having ethics lectures or courses during their undergraduate studies and those who did basic research had higher RMSS scores. There was also a trend towards respondents having higher RMSS scores if they had pursued their doctoral studies for longer. There was no difference for gender.

Table 2 RMSS score for background variables

\begin{tabular}{|l|l|l|l|l|}
\hline RMSS score & Mean & Median & SD & N \\
\cline { 1 - 5 } Location of UG studies & 1.62 & 0.0 & 3.53 & 91 \\
\hline Norway & $4.18^{* *}$ & 2.0 & 4.88 & 34 \\
\hline Sweden & 1.83 & 2.0 & 1.60 & 6 \\
\hline Other & & & & \\
\hline $\begin{array}{l}\text { Science ethics lectures or } \\
\text { courses during UG study }\end{array}$ & & & & \\
\hline Yes & 1.84 & 0.0 & 3.34 & 89 \\
\hline No & $4.83^{* *}$ & 3.0 & 5.46 & 24 \\
\hline Can't remember & 1.25 & 0.0 & 3.80 & 16 \\
\hline & & & & \\
\hline Kind of research conducted & & & & \\
\hline Clinical & 1.59 & 0.0 & 3.28 & 76 \\
\hline Basic & $4.26^{*}$ & 2.0 & 5.25 & 35 \\
\hline Other & 1.75 & 0.5 & 3.09 & 16 \\
\hline & & & & \\
\hline Duration of doctoral research+ & & & & \\
\hline Less than 1 year & 2.15 & 0.0 & 3.99 & 98 \\
\hline 1-2 years & 3.07 & 1.0 & 4.39 & 27 \\
\hline
\end{tabular}




\begin{tabular}{l|l|l|l|l|}
\hline More than 2 years & 1.50 & 1.50 & 1.29 & 4 \\
\hline
\end{tabular}$\quad * * p=0.05 \quad 0.005 K r u s k a l l-W a l l i s ~ t e s t$ followed by Mann-Whitney test for pair-wise differences
$+p=<0.05$ Jonckheere-Terpstra test for trend

Comparing the self-reports of misconduct elicited by the questions derived from Nilstun et al and the RMSS shows that the RMSS elicits a higher rate of self-reporting for equivalent behaviors if compared to both definite 'Yes' answers in the Nilstun questionnaire and the combination of 'Yes' and 'Uncertain' answers (see Table 3).

Table 3 Comparison of self-reports of misconduct

\begin{tabular}{|l|l|l|l|}
\hline Type of Misconduct & $\begin{array}{l}\text { Nilstun } \\
\text { 'Yes' }\end{array}$ & Nilstun 'Yes' + 'Uncertain' & RMSS \\
\hline Fabricated data & 1 & 1 & $2+$ \\
\hline Falsified data & 1 & 1 & $3++$ \\
\hline Plagiarised publication & 0 & 2 & $11+++*$ \\
\hline
\end{tabular}

The results show a correlation between attitudes as measured by the Kalichman scale and behavior as measured by RMSS. The more the respondent's attitudes were in accordance with ordinary norms of scientific integrity, the lower were the Research Misbehavior Severity Scores (RMSS). The same goes for their attitudes to whistleblowing. There does not appear to be any correlation with respect to the respondents' attitudes to punishment for scientific misconduct. See Table 4 The Kalichman scale had a mean of 53.24 (SD 6.36) and the RMSS had a mean of 2.29 (SD 4.00). Of the respondents who completed the RMSS 56 out of 131 (42.7\%) reported at least one misbehavior.

Table 4 Correlation between Kalichman Attitude Towards Misconduct Scale and Research Misbehavior Severity Score (RMSS)

\begin{tabular}{|l|c|c|c|}
\hline & $\begin{array}{c}\text { Correlation } \\
\text { coefficient - } \\
\text { Spearman rho }\end{array}$ & SE & p value \\
\hline $\begin{array}{l}\text { Kalichman 13 item } \\
\text { scale }\end{array}$ & -.256 & .089 & .004 \\
\hline $\begin{array}{l}\text { General attitude } \\
\text { sub-scale }\end{array}$ & -.247 & .089 & .005 \\
\hline Personal sub-scale & -.154 & .086 & .083 \\
\hline $\begin{array}{l}\text { Whistleblowing } \\
\text { sub-scale }\end{array}$ & -.324 & .076 & $<0.0005$ \\
\hline $\begin{array}{l}\text { Punishment sub- } \\
\text { scale }\end{array}$ & .079 & .087 & .371 \\
\hline
\end{tabular}

Details for the Kalichman results, RMSS results and for the questions on actions and knowledge are given in supplementary tables S1-S3 in the Appendix.

Two of the more commonly admitted misbehaviors in the RMSS have related items or scales elsewhere in the questionnaire and we therefore decided to explore any potential statistical correlations. The analysis show that the RMSS item "Turned a blind eye to colleagues' use of flawed 
data or questionable interpretation of data?" and the Kalichman Whistleblowing sub-scale are negatively correlated (Spearman rho -.198, SE .071, $p=0.018$, dns) And the RMSS item "Added one or more authors to a report who did not qualify for authorship (honorary author)?" is positively correlated to the item "Have you during the last 12 months been exposed to unethical pressure concerning inclusion or ordering of authors?" (Spearman rho .280, SE .103, $p=0.001$, dns).

\section{Discussion}

The survey had a high response rate, but there are also some weaknesses in the study. Asking people to self-report behavior that they know is perceived as problematic and socially unacceptable is likely to lead to under-reporting, even if all possible steps have been taken to ensure anonymity. The reported incidence of misbehaviour must thus be taken as the lower bound of the actual incidence.

The respondents were all doctoral students, and therefore early in their scientific careers and most respondents were furthermore relatively early in their doctoral studies. They thus had limited exposure to the research environment and limited time to commit any research misbehaviors. This is to some extents substantiated by the trend in RMSS scores according to length of doctoral study. This must be taken into account when interpreting the results. Another weakness is that all of the respondents were pursuing their studies at the same institution which may limit the generalisability of the results.

The four most common reported research misbehaviors are:

- Added one or more authors to a report who did not qualify for authorship (honorary author) (17.9\%)

o Decided to collect more data after seeing that the results were almost statistically significant (11.8\%)

o Turned a blind eye to colleagues' use of flawed data or questionable interpretation of data $(11.2 \%)$

o Reported an unexpected finding as having been hypothesized from the start (10.5\%)

These numbers are lower than those found by Tijdink et al using the RMSS in a sample of Dutch biomedical research scientists (Tijdink et al. 2016), but this may be due to the fact that our respondents have not all had 3 years research experience and the reported research misbehavior incidence may therefore not in reality be a 3 year incidence but reflect a shorter time period.

The RMSS seems to elicit more self-reporting of misconduct than the questions originally used by Nilstun et al where questions are directly comparable (Nilstun, Lofmark, and Lundqvist 2010). There may be several explanations for this. The answer formats are different and it may be less difficult for respondents to admit to misconduct by ticking the lower of four increasing frequencies of misconduct, than by ticking a fairly stark 'Yes'. The time period respondents are asked to consider is also different, 12 months for the Nilstun questions, 3 years for the RMSS.

We find that there is correlation between doctoral candidates' attitudes and their self-reported behavior. This result is expected and is evidence of the concurrent validity of both instruments, i.e. the Kalichman scale for measuring attitudes and the RMSS for measuring behavior. Given that the 
data are generated by a cross-sectional survey it is not possible to indicate if the correlation indicates causality or what direction any causal link might have. It may be that attitudes influence behavior, or that behavior changes attitudes.

The fact that we do not find any gender differences with respect to RMSS is in accordance with other research (Fanelli, Costas, and Larivière 2015). We do, however find some relations between reported misbehaviors and other background factors. The results show that place of undergraduate studies was correlated with RMSS results. Having studied in Sweden was associated with significantly higher reported research misconduct. To some extent this is compatible with a previous study studying doctoral students in Norway and Sweden (Hofmann et al. 2015a). There may be many reasons for this. The recruitment of PhD candidates from Sweden to Norway may be biased in some way or there may be differences in academic cultures in Sweden and Norway, although the overall structure and contents of undergraduate studies in the biomedical sciences are very similar in the two countries. Moreover, the teaching on ethics and research integrity may be different in the two countries. However, it is somewhat puzzling that the RMSS score for the doctoral candidates that did their undergraduate studies in other countries (than Norway and Sweden) is comparable to those in Norway, although the number of 'foreign' students is small. It is generally acknowledge that regional and cultural differences are important in relation to attitudes towards and incidence of scientific misconduct (Ana et al. 2013).

Our finding that previous ethics education is associated with lower RMSS is of course encouraging. The effect seen is relatively large, but other studies have shown moderate results from ethics teaching on research integrity (Anderson et al. 2012, Kaiser 2014). There is no obvious explanation for the difference between our study and the other studies.

Our finding that doctoral candidates doing basic research report higher RMSS is also difficult to interpret.

In the questionnaire the questions about background factors come before the questions about behaviors and attitudes. It could therefore be the case that the respondents have generated a particular view of the 'demand characteristics' of the task from the demographic questions, and that the differences found in relation to previous ethics education are fully explainable as a response to perceived demand characteristics (McCambridge, De Bruin, and Witton 2012). That is, respondents who have previous ethics education 'know' that the researchers want to see a positive effect of this and answer accordingly. An appeal to demand characteristics is, however unable to explain differences found in relation to place of undergraduate study and type of research being conducted.

We also find that candidates that are prone to "turn a blind eye" have less positive attitudes towards whistleblowing. Moreover, we find that persons who experience pressure with respect to authorship are more likely to have added honorary authors. Here we must again emphasise that correlation is not proof of causality, or the direction of causality.

There is an international debate on which terms to use for scientific misconduct (misbehavior, questionable research practice, fraud etc). This debate is important but we have not engaged with it in this project, but used the terms most convenient to the context. 


\section{Conclusion}

This study shows that there is a correlation between attitudes towards scientific misconduct and selfreported problematic scientific behaviors among doctoral students in biomedicine. Although the direction of causality cannot be determined in this study the correlation may indicate the importance of engendering the right values and attitudes in early career researchers. This is further emphasised by our findings that there are correlations between scientific misbehavior and the location of undergraduate studies and whether or not the respondents have had science ethics lectures or courses in their undergraduate studies.

The study also provides evidence for the concurrent validity of the Kalichman scale for measuring attitudes and the RMSS for measuring behavior.

\section{Acknowledgement}

We thank Joeri K. Tijdink for permission to use the Research Misbehavior Severity Score.

\section{References}

Ana, J., T. Koehlmoos, R. Smith, and L. L. Yan. 2013. "Research misconduct in low- and middle-income countries." PLoS Med 10 (3):e1001315. doi: 10.1371/journal.pmed.1001315.

Anderson, E. E., S. Solomon, E. Heitman, J. M. DuBois, C. B. Fisher, R. G. Kost, M. E. Lawless, C. Ramsey, B. Jones, A. Ammerman, and L. F. Ross. 2012. "Research ethics education for community-engaged research: a review and research agenda." J Empir Res Hum Res Ethics 7 (2):3-19. doi: 10.1525/jer.2012.7.2.3.

Anderson, M. S., B. C. Martinson, and R. De Vries. 2007. "Normative dissonance in science: results from a national survey of u.s. Scientists." J Empir Res Hum Res Ethics 2 (4):3-14. doi: 10.1525/jer.2007.2.4.3.

Bakker, Marjan, and Jelte M Wicherts. 2011. "The (mis) reporting of statistical results in psychology journals." Behavior research methods 43 (3):666-678.

Bozeman, Barry, and Jan Youtie. 2016. "Trouble in Paradise: Problems in Academic Research Coauthoring." Science and Engineering Ethics 22 (6):1717-1743. doi: 10.1007/s11948-0159722-5.

Davis, M. S., M. Riske-Morris, and S. R. Diaz. 2007. "Causal factors implicated in research misconduct: evidence from ORI case files." Sci Eng Ethics 13 (4):395-414. doi: 10.1007/s11948-007-90452.

de Vries, R., M. S. Anderson, and B. C. Martinson. 2006. "Normal Misbehavior: Scientists Talk about the Ethics of Research." J Empir Res Hum Res Ethics 1 (1):43-50. doi: 10.1525/jer.2006.1.1.43.

DuBois, J. M., E. E. Anderson, J. Chibnall, K. Carroll, T. Gibb, C. Ogbuka, and T. Rubbelke. 2013. "Understanding research misconduct: a comparative analysis of 120 cases of professional wrongdoing." Account Res 20 (5-6):320-38. doi: 10.1080/08989621.2013.822248.

Fanelli, D. 2009. "How many scientists fabricate and falsify research? A systematic review and metaanalysis of survey data." PLoS One 4 (5):e5738. doi: 10.1371/journal.pone.0005738.

Fanelli, D. 2010. "Do pressures to publish increase scientists' bias? An empirical support from US States Data." PLoS One 5 (4):e10271. doi: 10.1371/journal.pone.0010271. 
Fanelli, Daniele, Rodrigo Costas, and Vincent Larivière. 2015. "Misconduct Policies, Academic Culture and Career Stage, Not Gender or Pressures to Publish, Affect Scientific Integrity." PLOS ONE 10 (6):e0127556. doi: 10.1371/journal.pone.0127556.

Fang, F. C., J. W. Bennett, and A. Casadevall. 2013. "Males are overrepresented among life science researchers committing scientific misconduct." MBio 4 (1):e00640-12. doi: 10.1128/mBio.00640-12.

George, Stephen L. 2016. "Research misconduct and data fraud in clinical trials: prevalence and causal factors." International journal of clinical oncology 21 (1):15-21.

Hofmann, B., G. Helgesson, N. Juth, and S. Holm. 2015a. "Scientific Dishonesty: A Survey of Doctoral Students at the Major Medical Faculties in Sweden and Norway." J Empir Res Hum Res Ethics 10 (4):380-8. doi: 10.1177/1556264615599686.

Hofmann, B., and S. Holm. 2016. "[Research misconduct: Knowledge, actions and attitudes of PhD candidates]." Journal for the Norwegian Medical Association 136 (17):1442-7. doi: 10.4045/tidsskr.16.0149.

Hofmann, B., A. I. Myhr, and S. Holm. 2013. "Scientific dishonesty--a nationwide survey of doctoral students in Norway." BMC Med Ethics 14:3. doi: 10.1186/1472-6939-14-3.

Hofmann, Bjørn, Gert Helgesson, Niklas Juth, and Søren Holm. 2015b. "Scientific Dishonesty: A Survey of Doctoral Students at the Major Medical Faculties in Sweden and Norway." Journal of Empirical Research on Human Research Ethics. doi: http://dx.doi.org10.1177/1556264615599686.

Holm, S., and B. Hofmann. 2017. "Investigating the Reliability and Factor Structure of Kalichman's "Survey 2: Research Misconduct" Questionnaire: A Post Hoc Analysis Among Biomedical Doctoral Students in Scandinavia." J Empir Res Hum Res Ethics:1556264617714658. doi: 10.1177/1556264617714658.

Jensen, L. B., K. O. Kyvik, R. Leth-Larsen, and M. B. Eriksen. 2018. "Research integrity among PhD students within clinical research at the University of Southern Denmark." Dan Med J 65 (4).

John, Leslie K, George Loewenstein, and Drazen Prelec. 2012. "Measuring the prevalence of questionable research practices with incentives for truth telling." Psychological science 23 (5):524-532.

Kaiser, M. 2014. "The integrity of science - lost in translation?" Best Pract Res Clin Gastroenterol 28 (2):339-47. doi: 10.1016/j.bpg.2014.03.003.

Kalichman, M. W., and P. J. Friedman. 1992. "A pilot study of biomedical trainees' perceptions concerning research ethics." Acad Med 67 (11):769-75.

Komic, D., S. L. Marusic, and A. Marusic. 2015. "Research Integrity and Research Ethics in Professional Codes of Ethics: Survey of Terminology Used by Professional Organizations across Research Disciplines." PLoS One 10 (7):e0133662. doi: 10.1371/journal.pone.0133662.

Lafollette, M. C. 2000. "The evolution of the "scientific misconduct" issue: An historical overview." Proc Soc Exp Biol Med 224 (4):211-5.

Martinson, B. C., M. S. Anderson, A. L. Crain, and R. de Vries. 2006. "Scientists' perceptions of organizational justice and self-reported misbehaviors." J Empir Res Hum Res Ethics 1 (1):5166. doi: 10.1525/jer.2006.1.1.51.

Martinson, B. C., A. L. Crain, M. S. Anderson, and R. De Vries. 2009. "Institutions' expectations for researchers' self-funding, federal grant holding, and private industry involvement: manifold drivers of self-interest and researcher behavior." Acad Med 84 (11):1491-9. doi: 10.1097/ACM.0b013e3181bb2ca6.

Marusic, A., L. Bosnjak, and A. Jeroncic. 2011. "A systematic review of research on the meaning, ethics and practices of authorship across scholarly disciplines." PLoS One 6 (9):e23477. doi: 10.1371/journal.pone.0023477.

McCambridge, Jim, Marijn De Bruin, and John Witton. 2012. "The effects of demand characteristics on research participant behaviours in non-laboratory settings: a systematic review." PloS one 7 (6):e39116. 
Nilstun, T., R. Lofmark, and A. Lundqvist. 2010. "Scientific dishonesty--questionnaire to doctoral students in Sweden." J Med Ethics 36 (5):315-8. doi: 10.1136/jme.2009.033654.

Okonta, P. I., and T. Rossouw. 2014. "Misconduct in research: a descriptive survey of attitudes, perceptions and associated factors in a developing country." BMC Med Ethics 15:25. doi: 10.1186/1472-6939-15-25.

Pryor, Erica R, Barbara Habermann, and Marion E Broome. 2007. "Scientific misconduct from the perspective of research coordinators: a national survey." Journal of Medical Ethics 33 (6):365-369.

Pupovac, Vanja, and Daniele Fanelli. 2015. "Scientists admitting to plagiarism: A meta-analysis of surveys." Science and engineering ethics 21 (5):1331-1352.

Ranstam, Jonas, Marc Buyse, Stephen L George, Stephen Evans, Nancy L Geller, Bruno Scherrer, Emmanuel Lesaffre, Gordon Murray, Lutz Edler, and Jane L Hutton. 2000. "Fraud in medical research: an international survey of biostatisticians." Controlled clinical trials 21 (5):415-427.

Redman, B. K., H. N. Yarandi, and J. F. Merz. 2008. "Empirical developments in retraction." J Med Ethics 34 (11):807-9. doi: 10.1136/jme.2007.023069.

Sarwar, U., and M. Nicolaou. 2012. "Fraud and deceit in medical research." J Res Med Sci 17 (11):1077-81.

Saurin, Tarcisio Abreu. 2016. "Ethics in Publishing: Complexity Science and Human Factors Offer Insights to Develop a Just Culture." Science and Engineering Ethics 22 (6):1849-1854. doi: 10.1007/s11948-015-9735-0.

Stern, A. M., A. Casadevall, R. G. Steen, and F. C. Fang. 2014. "Financial costs and personal consequences of research misconduct resulting in retracted publications." Elife 3:e02956. doi: 10.7554/eLife.02956.

Tijdink, J. K., R. Verbeke, and Y. M. Smulders. 2014. "Publication pressure and scientific misconduct in medical scientists." J Empir Res Hum Res Ethics 9 (5):64-71. doi: $10.1177 / 1556264614552421$.

Tijdink, Joeri K., Lex M. Bouter, Coosje L. S. Veldkamp, Peter M. van de Ven, Jelte M. Wicherts, and Yvo M. Smulders. 2016. "Personality Traits Are Associated with Research Misbehavior in Dutch Scientists: A Cross-Sectional Study." PLOS ONE 11 (9):e0163251. doi: 10.1371/journal.pone.0163251. 


\section{Appendix}

S1

Explanations of and details for the Kalichman 13 items scale, General attitude sub-scale, Personal sub-scale, Whistleblowing sub-scale, and Punishment sub-scale

\begin{tabular}{|c|c|c|c|}
\hline $\begin{array}{l}\text { Statement (Scored on } 5 \text { point Likert scale 1-5 from "Completely } \\
\text { disagree" to "Completely agree") } \\
\text { In forming the scale item } 7 \text { and } 8 \text { are reverse scored }\end{array}$ & Mean & SD & \\
\hline $\begin{array}{l}\text { Q1. It is never appropriate to report experimental data that have } \\
\text { been created without actually having conducted the experiment. }\end{array}$ & 4.55 & 1.02 & \multirow[t]{6}{*}{$\begin{array}{l}\text { General attitude towards } \\
\text { misconduct scale }\end{array}$} \\
\hline $\begin{array}{l}\text { Q2. It is never appropriate to alter experimental data to make an } \\
\text { experiment look better than it actually was. }\end{array}$ & 4.77 & .571 & \\
\hline $\begin{array}{l}\text { Q 3. It is never appropriate to try a variety of different methods } \\
\text { of analysis until one is found that yields a result that is } \\
\text { statistically significant. }\end{array}$ & 3.71 & 1.02 & \\
\hline $\begin{array}{l}\text { Q4. It is never appropriate to take credit for the words or writing } \\
\text { of someone else. }\end{array}$ & 4.59 & .771 & \\
\hline $\begin{array}{l}\text { Q5. It is never appropriate to take credit for the data generated } \\
\text { by someone else. }\end{array}$ & 4.42 & .919 & \\
\hline $\begin{array}{l}\text { Q6. It is never appropriate to take credit for the ideas generated } \\
\text { by someone else. }\end{array}$ & 4.40 & .907 & \\
\hline $\begin{array}{l}\text { Q7. If you are confident of your findings, it is acceptable to } \\
\text { selectively omit contradictory results to expedite publication. }\end{array}$ & 1.97 & 1.20 & \multirow{2}{*}{$\begin{array}{l}\text { Attitude to personal } \\
\text { misconduct scale (reverse } \\
\text { scored) } \\
\text { Score }=3.59 \\
\mathrm{SD}=2.33\end{array}$} \\
\hline $\begin{array}{l}\text { Q8. If you are confident of your findings, it is acceptable to } \\
\text { falsify or fabricate data to expedite publication. }\end{array}$ & 1.62 & 1.28 & \\
\hline $\begin{array}{l}\text { Q9. It is more important that data reporting be completely } \\
\text { truthful in a publication than in a grant application. }\end{array}$ & 2.87 & 1.32 & Excluded \\
\hline $\begin{array}{l}\text { Q10. If you witness someone committing research misconduct, } \\
\text { you have an ethical obligation to act. }\end{array}$ & 4.17 & .812 & Whistleblowing scale \\
\hline $\begin{array}{l}\text { Q11. If you had witnessed a co-worker or peer committing } \\
\text { research misconduct, you would be willing to report that } \\
\text { misconduct to a responsible official. }\end{array}$ & 3.91 & .817 & \multirow[t]{2}{*}{$\begin{array}{l}\text { Score }=11.9 \\
\text { SD }=2.21\end{array}$} \\
\hline $\begin{array}{l}\text { Q12. If you had witnessed a supervisor or principal investigator } \\
\text { committing research misconduct, you would be willing to report } \\
\text { that misconduct to a responsible official. }\end{array}$ & 3.84 & .839 & \\
\hline $\begin{array}{l}\text { Q13. If fabricated data are discovered in a published paper, all } \\
\text { co-authors must equally share in the blame. }\end{array}$ & 3.56 & 1.04 & \multirow{2}{*}{$\begin{array}{l}\text { Punishment scale } \\
\text { Mean }=6.40 \\
\text { SD }=1.91\end{array}$} \\
\hline $\begin{array}{l}\text { Q14. If fabricated data are discovered in a published paper, all } \\
\text { co-authors must get the same punishment. }\end{array}$ & 2.84 & 1.07 & \\
\hline
\end{tabular}

Table S2 Results for the Research Misbehavior Severity Score for each behavior

\begin{tabular}{|c|c|c|c|c|c|}
\hline Behavior & 0 times & Once & $\begin{array}{l}\text { Multiple } \\
\text { times }\end{array}$ & Regularly & Always \\
\hline 1. Fabricated data? & 146 & 2 & & & \\
\hline $\begin{array}{l}\text { 2. To confirm a hypothesis, selectively deleted or changing } \\
\text { data after performing data analysis? }\end{array}$ & 143 & 2 & 1 & & \\
\hline 3. Deleted data before performing data analysis? & 142 & 3 & 1 & 2 & \\
\hline $\begin{array}{l}\text { 4. Concealed results that contradicted previous research you } \\
\text { published? }\end{array}$ & 146 & 1 & & & \\
\hline 5. Used phrases or ideas of others without their permission? & 136 & 6 & 5 & & \\
\hline
\end{tabular}




\begin{tabular}{|c|c|c|c|c|c|}
\hline 6. Used/ing phrases or ideas of others without citation? & 136 & 5 & 6 & & \\
\hline $\begin{array}{l}\text { 7. Turned a blind eye to colleagues' use of flawed data or } \\
\text { questionable interpretation of data? }\end{array}$ & 127 & 14 & 2 & & \\
\hline $\begin{array}{l}\text { 8. Modified the results or conclusions of a study under } \\
\text { pressure from an organization that (co-) funded the research? }\end{array}$ & 137 & 5 & 2 & & \\
\hline 9. Not published (part of) the results of a study? & 130 & 7 & 5 & 1 & \\
\hline $\begin{array}{l}\text { 10. Deliberately not mentioned an organization that funded } \\
\text { your research in the publication of your study? }\end{array}$ & 141 & 3 & & & \\
\hline $\begin{array}{l}\text { 11. Added one or more authors to a report who did not qualify } \\
\text { for authorship (honorary author)? }\end{array}$ & 119 & 20 & 6 & & \\
\hline $\begin{array}{l}\text { 12. Selectively modified data after performing data analysis to } \\
\text { confirm a hypothesis? }\end{array}$ & 136 & 6 & 1 & & \\
\hline $\begin{array}{l}\text { 13. Reported/ing a downwardly rounded } p \text { value (e.g. } \\
\text { reporting that a p value of } .054 \text { is less than } .05) \text { ? }\end{array}$ & 140 & 3 & 1 & & \\
\hline $\begin{array}{l}\text { 14. Reported an unexpected finding as having been } \\
\text { hypothesized from the start? }\end{array}$ & 128 & 12 & 2 & 1 & \\
\hline $\begin{array}{l}\text { 15. Decided whether to exclude data after looking at the } \\
\text { impact of doing so on the results? }\end{array}$ & 134 & 7 & 4 & & \\
\hline $\begin{array}{l}\text { 16. Decided to collect more data after seeing that the results } \\
\text { were almost statistically significant? }\end{array}$ & 127 & 9 & 4 & 3 & 1 \\
\hline $\begin{array}{l}\text { 17. Omitted a contributor who deserved authorship from the } \\
\text { author's list? }\end{array}$ & 141 & 2 & 1 & & \\
\hline $\begin{array}{l}\text { 18. Stopped collecting data earlier than planned because the } \\
\text { result at hand already reached statistical significance without } \\
\text { formal stopping rules? }\end{array}$ & 140 & 1 & 3 & & \\
\hline $\begin{array}{l}\text { 19. Deliberately failed to mention important aspects of the } \\
\text { study in the paper? }\end{array}$ & 141 & 1 & 2 & & \\
\hline $\begin{array}{l}\text { 20. Not disclosed a relevant financial or intellectual conflict of } \\
\text { interest? }\end{array}$ & 141 & 2 & 1 & & \\
\hline $\begin{array}{l}\text { 21. Spread results over more papers than needed to publish } \\
\text { more papers ('salami slicing')? }\end{array}$ & 139 & 4 & 2 & & \\
\hline $\begin{array}{l}\text { 22. Used confidential reviewer information for own research } \\
\text { or publications? }\end{array}$ & 144 & 1 & & & \\
\hline
\end{tabular}


Table S3 Results for actions and knowledge

\begin{tabular}{|c|c|c|c|}
\hline $\begin{array}{l}\text { Have you yourself during the last } 12 \\
\text { months been the object of pressure } \\
\text { to }\end{array}$ & Yes & No & Uncertain \\
\hline - $\quad$ Fabricate data & 0 & 149 & 0 \\
\hline - Falsify data & 2 & 147 & 0 \\
\hline - $\quad$ Plagiarise data & 1 & 148 & 0 \\
\hline $\begin{array}{l}\text { - } \begin{array}{l}\text { Plagiarise publications (in } \\
\text { whole or in part) }\end{array} \\
\end{array}$ & 1 & 148 & 0 \\
\hline $\begin{array}{l}\text { - Present results in some other } \\
\text { misleading way }\end{array}$ & 2 & 125 & 9 \\
\hline \multicolumn{4}{|l|}{$\begin{array}{l}\text { Have you yourself during the last } 12 \\
\text { months ever }\end{array}$} \\
\hline - $\quad$ Fabricated data & 1 & 148 & 0 \\
\hline - $\quad$ Falsified data & 1 & 148 & 0 \\
\hline - $\quad$ Plagiarised data & 0 & 149 & 0 \\
\hline $\begin{array}{l}\text { - Plagiarised publications (in } \\
\text { whole or in part) }\end{array}$ & 0 & 147 & 2 \\
\hline 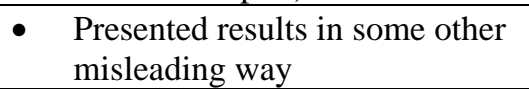 & 1 & 135 & 4 \\
\hline \multicolumn{4}{|l|}{$\begin{array}{l}\text { Do you know about anyone in your } \\
\text { department who during the last } 12 \\
\text { months has }\end{array}$} \\
\hline - $\quad$ Fabricated data & 1 & 146 & 2 \\
\hline - $\quad$ Falsified data & 2 & 142 & 3 \\
\hline - $\quad$ Plagiarised (in any way) & 2 & 146 & 1 \\
\hline $\begin{array}{l}\text { - Presented results in some other } \\
\text { misleading way }\end{array}$ & 3 & 138 & 6 \\
\hline \multicolumn{4}{|l|}{$\begin{array}{l}\text { Have you during the last } 12 \text { months } \\
\text { been exposed to unethical pressure } \\
\text { concerning }\end{array}$} \\
\hline - Inclusion or ordering of authors & 15 & 126 & 7 \\
\hline - $\quad$ Design/method & 0 & 144 & 5 \\
\hline - Analysis & 2 & 143 & 4 \\
\hline - $\quad$ Results & 3 & 142 & 4 \\
\hline
\end{tabular}

